\title{
Needs of Senior Citizens Participating in the Design of University Courses
}

\author{
Chien-Hui Yang and Jui-Ying Hung
}

\begin{abstract}
Aging population structures have become a global development trend. In Taiwan, the progressive aging of the population has resulted in the emergence of new industrial dimensions and issues. According to the 2011 statistics announced by the Department of Household Registration, there were approximately 2.6 million citizens over the age of 65 by the end of 2011. In Taiwan's aging society structure, senior citizens demonstrate greater self-perseverance, and successively participate in community lifelong learning based on their personal intentions to achieve the goals of self-satisfaction and life fulfillment.
\end{abstract}

Index Terms - Senior, elderly learning, learning needs.

\section{INTRODUCTION}

The average life expectancy in 2012 was a 0.30 -year increase from 2010, which was a result of advances in technology. Subsequently, the percentile of the population aged 65 and above reached $11.15 \%$ in Taiwan in 2011, presenting an age index of $76.21 \%$. In preparation for an aging population, Taiwanese society has included numerous learning options and institutes to accommodate senior citizens, and governmental and non-governmental units have endeavored to resolve senior citizen education issues and maintain related welfare. Among these learning options, senior citizens typically select a preferred option to engage in lifelong learning. Thus, satisfying the learning needs of senior citizens would inevitably influence their selection preferences. In this context, courses designed by various institutes influence the participation of senior citizens. For example, senior citizen learning courses, which are an option strategized by the Taiwanese government and hosted by numerous schools, are favored by senior citizens. Therefore, senior citizens' selection of learning options and course design are critical aspects in the promotion of senior citizen learning.

The present study focuses on senior citizens' learning needs for senior citizen education following the post-war baby boom. In addition, a comparative analysis was performed on the fundamental demographic variables of senior citizens and their course needs and satisfaction. The

Manuscript received October 23, 2013; revised December 29, 2013.

Chien-Hui Yang is with the Adult and Continuing Education, National Chung Cheng University, No.168, Sec. 1, University Rd., Min-Hsiung Township, Chia-yi County 621, Taiwan ROC (e-mail: ssabc2002@gmail.com).

Jui-Ying Hung is with the Department of Golden-Ager Industry Management, Chaoyang University of Technology, 168, Jifeng E. Rd, Wufeng District, Taichung City 41349, Taiwan ROC (e-mail: jybong@cyut.edu.tw). comparison results were then examined to investigate whether the gender and education differences of senior citizens influence their course needs and satisfaction. Thus, the primary objectives of the present study were as follows:

1) To investigate the influences and relationships that different gender variables have on the learning needs and satisfaction of senior citizens, and to compare the interrelations between the various influences and senior citizen participation.

2) To better understand course planning for senior citizen education by surveying the learning needs of senior citizens.

3) To understand the senior citizens' satisfaction toward the current senior citizen education conditions by administering a questionnaire survey, and to determine whether the courses offered comply with the needs of senior citizens by examining the survey results.

The respondents in this study were primarily recruited by referencing the enrollment criteria of the senior citizen learning courses established by the Ministry of Education. To participate, subjects must meet the following criteria: (1) be a student in a senior citizen learning course; (2) be 55 years or older; and (3) be in good health. Consequently, the subjects' levels of education were not considered. The research scope encompassed the senior citizen learning courses hosted by various colleges and universities in Taiwan.

\section{PRocedure For PAPER SUBMISSION}

\section{A. Factors Influencing Learning}

A literature review showed that senior citizens' learning needs for various courses are influenced by their demographic characteristics (Kou, 2003 [1]; Lin, 2007 [2]). Thus, the intrinsic qualities of senior citizens place a specific extent of influence on their learning preferences. Kuo (2003) [1] found that characteristics of gender, age, education level, and health influence senior citizens' learning needs with regard to courses. As cited in Lin (2007) [2], Williamson (2000) and Lai (1990) [3] asserted that gender influences the content of senior citizen learning. Huang and Wu (2007) [4] studied a group of middle-aged and senior women studying supplementary courses in an elementary school. The researchers found that characteristics of gender and family class influenced the course perspectives of the subjects, and contended that this influence was because of varying backgrounds and stereotypical limitations. Wei (2008) [5] reported that characteristics of cultural background, ethnicity, gender, class, and age influence individual learning performance. This researcher also contended that the 
urban-rural gap is a critical factor influencing learning. However, extant studies pertaining to senior citizen education have seldom emphasized this factor. The present study further contends that regional differences are also a critical factor resulting in discrepancies in learning needs because a city typically comprises districts with varying levels of prosperity. Weng (2010) [6] indicated that interesting and practical courses that are designed based on gender and education level would better conform to the learning needs of senior citizens. Yoh (2010) [7] indicated that education level, financial status, and health conditions influence the learning intentions of senior citizens.

Similar to the results of Kuo, Pearce (1991) [1] asserted that the characteristics pertaining to the participation in learning activities by senior citizens include age, gender, education level and social status, health, learning preference, reason for participation, and participation obstructions. Below, a brief introduction is provided for each characteristic.

1) Age: The majority of senior citizens who engage in learning activities are between the ages of 60 and 64 years old, and participation rapidly declines after individuals reach 64 years of age.

2) Gender: The participation of women is greater than that of men.

3) Education Level and Social Status: Numerous previous studies have found that educational achievement, social status, and learning activity participation are positively correlated. Among these characteristics, educational achievement is most effective in predicting the learning conditions of senior citizens, which is primarily because low educational achievement causes senior citizens to lose confidence in learning; in contrast, increased confidence can be generated with high educational achievement.

4) Health: Numerous studies have asserted that health conditions are a primary consideration for senior citizens when engaging in learning.

5) Learning Preference: Studies have shown that senior citizens increasingly prefer expressional course with age.

6) Reason for Participation: The key reasons for senior citizens' participation in learning include self-development, learning interest, seeking intellectual stimulation, and increasing the opportunity to engage in discussions with others, among other reasons.

7) Participation Obstructions: Numerous factors, such as low confidence, a lack of course messages, time and transport issues, and distance to and convenience of the learning institute, potentially obstruct the participation of senior citizens.

According to the demographic characteristics proposed in the aforementioned studies, gender, age, education level, family class, residency, financial situation, and health conditions, among other factors, influence learning needs and intentions. Thus, for the design of senior citizen learning courses, educational institutes should base their designs on these characteristics to comply with the specific learning needs of learners.

\section{B. Learning Needs}

In their theory regarding senior citizens' learning needs, McClusky (1971) [8] and Moody (1976) [9] both asserted that senior citizens' exhibit transcending or self-realizing needs. Thus, if the learning needs of senior citizens could reflect their individual development and enable them to acquire practical knowledge and techniques for self-development that balance the impacts caused by development, learning demands can be satisfied. In addition, the learning process will become more appealing and effective, thereby enhancing the cognitive capability and self-development of seniors. Knowles (1980) [10] contended that learning needs are, in actuality, education needs, that individuals desire to learn to create the self, organizations, or social benefits. The nature of these needs can be identified in the margin between actual conditions and expectations. People demonstrate varying learning needs in various development stages, and the results of each development stage become the motivation for lifelong learning (Huang, 1993) [11].

According to the "Survey Report on the Learning Needs and Intentions of Senior Citizens in Taiwan," Huang (2008) [12] contended that the learning needs of senior citizens refer to the desire to fulfill the inadequacies in their perceptions, and these inadequacies can only be fulfilled to an ideal level through learning. Consequently, Huang categorized learning needs into family and interpersonal relationships, healthcare, leisure and entertainment, society and politics, self-realization and the meaning of life, and retirement planning and adaptation, and defined senior citizen learning as the learner's physical, emotional, utilitarian, cognitive, and social performances within a learning environment during the learning process. Then, for the aforementioned study, the 5 performance factors were revised into learning time, learning location, teaching method, teacher's attributes, and number of learners per class to investigate the learning performance of senior citizens.

According to the "Survey Report on the Current Status for Senior Education Promotion and Learning Needs in Taiwan," Wei (2006) [5] categorized the needs of senior citizens involved in the learning process into several major categories to examine the learning performance of senior citizens.

1) Product: course content, course time arrangement, mode of attendance, number of learners per class, learner's age, and other related service measures

2) Price: course tuition, charging method

3) Recruitment: marketing method

4) Location: learning environment

5) Professionals: administrative personnel, teachers, training professionals

The "Survey Report on the Current Status for Senior Educational Promotion and Learning Needs in Taiwan" is a research report on senior citizen learning proposed by the Ministry of Education in 2006. This report categorized learning needs into the following subjects: leisure (i.e., sports, arts, crafts, theater, and travel), language training, computer and information, healthcare and physiological adjustment, karaoke and singing, dancing, ideology (i.e., philosophy and religion), volunteer training, financial and economics 
management, humanities (i.e., literature, biography, and history), basic literacy education, skill training for re-employment, public affairs (i.e., civil rights, law, and politics), and others.

Based on the arguments provided by the aforementioned scholars, learning needs can be defined as the insufficiencies perceived by an individual who, through participating in a specific course, perceives that these insufficiencies can be improved. Subsequently, according to these arguments, learning needs can be categorized into the following types:

1) Leisure: singing, outdoor education, and dancing class, among others.

2) Information and Technology: computer studies and novel technological products (assistive technologies), among others.

3) Psychology and Adaptation: stress relief and psychological adjustment, among others.

4) Healthcare: drug use, disease prevention, and health and fitness, among others.

5) Financial Management: retirement financial planning and insurance, among others.

6) Social Participation and Relations: communication courses, socialization, interpersonal relationships, intergenerational relationships, and voluntary services, among others.

7) Literature and Arts: philosophy appreciation, language learning, film and music appreciation, and art classes, among others.

8) Senior CitizenCourses: delaying aging, understanding aging, and the meaning of death, among others.

\section{Course Content}

In education, the actual learners are students. Educators' efforts in designing course content or teaching are devalued when students undermine learning or when they perceive the course as being unproductive (Huang and Wu, 2007) [4] This is also relevant when planning senior citizen education courses. Thus, when designing relevant courses, information such as extant literature, newspaper articles, and magazine reports can be collected and used as a reference in identifying and designing course types and contents that are consistent with the learning needs of senior citizens.

Huang (2002) [13] contended that senior citizen education in Taiwan shows a general preference for functionalism. This can be observed from the types of courses offered, which are typically leisure-related courses introduced in the admission guides offered by numerous senior citizen education institutes (e.g., the Kao-Hsiung Institute of Aging and Songbo University), and which effectively hinder senior citizen education in Taiwan from truly serving senior citizens. According to the White Paper on Senior Education announced by the the Lifelong Learning Department (formally known as the Social Education Department), Ministry of Education, in 2006, the majority of senior citizen learning courses and activities offered in Taiwan are based on social welfare and leisure. In addition, the recruitment age for community colleges is not restricted, and thus courses offered in these colleges are not specifically designed for senior citizens.

Among the various senior citizen education institutes, Lin
(2007) [2] analyzed the courses offered by 2 institutes using purposive sampling. Results showed that these institutes primarily provided courses that trended toward functionalism, where language courses were primarily provided, leisure courses were preferred, computer and information courses received gradual attention, and healthcare courses were necessitated. Subsequently, based on the end-of-term reports proposed by the Senior Citizens Resource Center, Wei (2009) [14] indicated that as of March 2009, the center had established over 750 courses, including country reminiscence, healthcare, Hakka culture, local industry, arts, and itinerant courses. The researcher asserted that the center provided more diverse courses when compared to conventional senior citizen education institutes, but that the depth and comprehensiveness of the course content required improvement (Wei and Shih, 2009) [15].

Analyzing extant literature pertaining to senior citizen education, Zhuang, Wei, and Huang (2008) [16] reported that the focal attention of numerous senior citizen education studies comprise 5 themes, specifically course, budget, marketing and propagation, venue and location, and professional staff. In addition, using purposive sampling principles, Lin (2007) [2] analyzed the courses offered by 2 senior citizen education institutes and used the analytical results to identify the future course planning trends of these institutes.

According to the course content regulations advocated by the "2011 Grants for the Planning Senior Citizens Learning Courses in Colleges and Universities Provisioned by the Ministry of Education," which is an extant research report for senior citizen learning announced by the Ministry of Education, course type and content should include the following 4 items:

1) Aging and Senior Citizen Courses: Understanding the trends of and measures against aging, such as the learning characteristics of senior citizens, successful aging, lifelong learning and localized aging, career planning, maintaining and handling interpersonal relationships, psychological stress and relief methods, and the meaning of life, among others.

2) Healthcare, Leisure, and Entertainment Courses: disease prevention for senior citizens (i.e., dementia, depression; compulsory), drug use and suicide prevention (compulsory), healthcare, mental health, health and fitness, travel education, and art appreciation, among others.

3) Specialty Courses: Courses designed based on the specialty or primary field of the host school, such as life care (compulsory), tourism and guided tours, technology and digital media, and arts, among others.

4) Life Knowledge Courses: Understanding the knowledge needed in contemporary society, such as transportation safety for senior citizens (compulsory), novel technological products, environmental protection trends, humanities and arts, and civil law, among others. In addition, the general university courses or other courses can be integrated into senior citizen education courses.

Course design is critical in satisfying the objectives of senior citizen lifelong learning. However, course design must achieve equilibrium between demand and supply. To attract a 
greater number of senior citizens, managers must identify the needs of senior citizens, and design relevant course content based on these needs; thereby satisfying the purpose of participation, increase the number of respondents, and achieve the lifelong learning goals established by the Ministry of Education. Moreover, learning preferences pertaining to equipment, professional staff, and environment also influence learning effectiveness during the learning process. Thus, the provision of appropriate courses must be combined with favorable learning preferences; thereby enhancing the learning quality of senior citizens.

\section{Methodology AND Research Procedures}

\section{A. Survey Method}

The sample population for this study was senior citizens aged 55 or above who participated in senior citizens learning courses accepted by the Ministry of Education. A general survey method was employed for sampling, examining every student that was currently participating in senior citizens learning courses to collect comprehensive research data.

\section{B. Response Rate}

A total of 96 schools that hosted senior citizens learning courses were examined in the present study. Based the 20 to 30 student limit for each senior citizens learning course established by the Ministry of Education, the present study administered a total of 1200 questionnaires; of which, 1026 valid questionnaires were returned, for a valid response rate of $85.5 \%$.

\section{Questionnaire Design}

The present study devised a closed-form questionnaire for preliminary data collection (See Table I). A 5-point Likert scale was incorporated into the questionnaire to measure the attitudes of the respondents. The respondents were instructed to select an answer for each item (very satisfied, satisfied, neutral, unsatisfied, and very unsatisfied) based on the intensity of their perceived emotions.

TABLE I: THE STRUCTURE OF THE QUESTIONNAIRE

\begin{tabular}{|c|c|}
\hline Scale & Evaluation Indicator \\
\hline $\begin{array}{l}\text { Factors } \\
\text { influencin } \\
\text { g learning }\end{array}$ & $\begin{array}{l}\text { - Courses established by the various host } \\
\text { schools } \\
\text { - Learning needs of senior citizens } \\
\text { - Senior citizens' Reponses to course } \\
\text { content }\end{array}$ \\
\hline $\begin{array}{l}\text { Demograp } \\
\text { hic data }\end{array}$ & Gender, age, and education level \\
\hline
\end{tabular}

\section{RESUlts}

\section{A. Learning Options}

The primary reason for senior citizens' participation in senior citizens learning courses was "enhancing relationships" ( $n=346 ; 33.7 \%)$, followed by "continuing education" ( $n=338 ; 32.9 \%)$. These results imply that the majority of the respondents participated in senior citizens learning courses in hopes of enhancing their relationships and interactions with others. For "continuing education," because numerous learning options are presented to senior citizens, "continuing education" was not the only options for senior citizens' participation in senior citizens learning courses. Thus, statistical results showed that "enhancing relationships" was the primary reason for their participation.

\section{B. Reasons for Preference}

The primary reason for senior citizens' preference for senior citizens learning courses was "course" ( $n=111$; $33.6 \%)$, followed by "teacher" $(n=85 ; 25.8 \%)$. This implies that the faculty was not the primary consideration factor for senior citizens; instead, course design was the primary factor attracting their participation.

\section{Factors Influencing Learning}

\section{1) Provided course content}

For the provided course types, the questionnaire survey results showed that "leisure" courses were selected by the majority of the respondents $(n=120 ; 15.5 \%)$, followed by "aging" courses $(n=110 ; 14.2 \%)$. The "other" courses were the least selected $(n=3 ; 0.4 \%)$. These statistics suggest that senior citizens learning courses most frequently provide leisure courses, anticipating providing senior citizens with more leisure related knowledge for them to plan and select. The aging course facilitates senior citizens in learning more knowledge relating to age and aging, and assists them in better preparing themselves for retirement.

2) The compliance of provided courses with the needs of senior citizens

The survey results for the established courses show that the course type most consistent with the needs of senior citizens were the "hygiene and healthcare" courses $(n=135 ; 95.7 \%)$, followed by the "aging" courses $(n=129 ; 91.5 \%)$. These statistics suggest that hygiene and health courses were most compliant with the needs of senior citizens, followed by aging courses. From these two course types, the researchers can infer that senior citizens anticipate learning more regarding their health and in terms of understanding the life of a senior citizen. Through these courses, senior citizens can acknowledge and plan their life following retirement in advance. In contrast, the most incompliant course for senior citizens was the "finance management" course $(n=22$; $15.6 \%)$. This result suggests that senior citizens lacked interest in financial management following retirement; thus indicating a low need for such courses.

\section{3) Overall satisfaction}

The respondents were the most satisfied with the "hygiene and health" courses ( $n=35$ for very satisfied, $24.8 \% ; n=79$ for satisfied, $56 \%$ ), followed by the "aging" courses $(n=30$ for very satisfied, $21.3 \% ; n=86$ for satisfied, $61 \%$ ). In contrast, the respondents were the most unsatisfied with the "financial management" courses ( $n=21$ for very satisfied, $14.9 \% ; n=57$ for satisfied, $40.4 \%$ ). These statistics show that most of the respondents were satisfied with the provided courses, with relatively lower satisfaction levels for financial management 
courses and higher satisfaction for hygiene and health and aging courses.

\section{4) Environment satisfaction}

Based on the survey results, the majority of the respondents were satisfied with the layout, distance, and location of the learning environment, but also indicated that they saw room for improvement. The results further show that although the course buildings comprised numerous floors and lengthy distances to the restrooms, the respondents were able to most of the respondents were healthy and were free from disabilities.

\section{5) Personnel satisfaction}

Overall, over $50 \%$ of the respondents were satisfied with their classmates, administrative personnel, and teachers in the senior citizens learning courses. The researchers of the present study maintain that although the learning needs of senior citizens vary, they demonstrate an extremely high satisfaction toward their teachers. This implies that respondents were satisfied with and respected the teachers that taught them.

\section{6) Analysis on respondents' demographics}

Of the 1026 valid questionnaires, male respondents comprised $262(25.5 \%)$ and female respondents comprised $764(74.5 \%)$. For age, the majority of the respondents were between the ages of 55 and $65(51.8 \%)$, followed by those between 66 and 75 (34.8\%). These results implied that most of the respondents were in the mid-elderly age group. For the number of senior citizen courses participated in, first-time participants accounted for the majority with 647 respondents (63.1\%), followed by second-time participants, who accounted for 291 respondents $(28.4 \%)$, and third-time and above participants, who accounted for 87 respondents $(8.5 \%)$.

\section{7) Cross-analysis between gender and reasons for participation}

Among the reasons for participating in senior citizen courses, the majority of the male respondents desired to improve relationships $(n=48,18.4 \%)$, followed by the desire for continuing education $(n=35,13.5 \%)$. In contrast, the majority of the female participants desired continuing education $(n=347,45.4 \%)$, followed by the desire to enhance relationships ( $n=319,41.8 \%)$.

8) Cross-analysis between gender and reasons for favoring senior citizen courses

The reasons why respondents favored senior citizen courses following participation were primarily course design $(n=56$ for men and 439 for women, $21.3 \%$ and $57.4 \%$, respectively) and their teachers (16.3\% for men and $44 \%$ for women). The course and overall score percentile for men was $83.3 \%$, which is comparatively higher than the $77.1 \%$ for women. These results imply men place greater emphasis on the primary reason for favoring senior citizen courses (course design) than women.

\section{9) Overall satisfaction for courses}

For overall satisfaction, 218 respondents (21.2\%) were very satisfied with their courses, followed by 590 respondents $(57.5 \%)$ who were satisfied with their courses. This indicates that the majority of the respondents were satisfied with their courses.

\section{REFERENCES}

[1] Y.-C. Kuo, A Study on the Effect between Lifestyle and Learning Needs of Older Adults in Elder College of Kaohsiung City, National Taiwan University, Taipei, Taiwan, 2003.

[2] L. H. Lin, "Analysis of the development trend of senior citizens learning content from educational institutions courses for senior citizens category," Curriculum and Instruction Quarterly, vol. 10, no. 1, pp. 83-96.

[3] R. H. Lai, "Research needs and related factors of elderly people to learn," Taiwan Normal University, Master Thesis, Institute of Social Studies, Taipei, 1990.

[4] H. W. Huang and X. M. Wu, "We want to identify the word: Small group of supplementary school students in elderly women Curriculum," Sociology of Education Research in Taiwan, vol. 7, no. 1, pp. 69-110, 2007.

[5] H. W. Yu, Taiwan's Education Elderly Related Dissertation Research Orientation of the School, 2008.

[6] C.-L. Weng, The Effect of Participant Motivation, Attitudes toward Aging and Participation Behavior of Elder, Co-operation with the Department of Finance, National Taipei University, New Taipei City, 2010.

[7] J. S. Yoh, Study of New Service Opportunity and Innovation on the Needs of Elderly Learning, 2010.

[8] H. Y. McClusky, White House Conference on Aging, 1971.

[9] Moody, The Older Adult as Learner: Aspects of Educational Gerontology, 1976.

[10] M. S. Knowles, The Modern Practice of Adult Education: from Andragogy to Pedagogy, New Jersey: Prentice Hall Regents, Englewood Cliffs, 1980.

[11] Huang, The key to successful aging. Adult Education, vol. 16, pp. 6-11, 1993.

[12] F. S. Huang, Retirement Age and Elderly People to Participate in the Learning Needs of Intentions Survey Report, the Ministry of Education, Taipei, 2008.

[13] C.-S. Huang, "New topic contemporary philosophy of education: Old educational philosophy Its Implications," Bulletin of Educational Research, vol. 48, no. 3, pp. 1-33, 2002.

[14] H.-C. Wei, M.-C. Hu, and C.-S. Huang, Taiwan to Promote the Status of the Elderly and Education Needs of the Investigation Report, the Ministry of Education, 2006.

[15] H.-C. Wei and Y.-Z. Shih, "The study of elderly educators curriculum planning capability assessment: A case study of learning resource centre seniors," Adult and Lifelong Education, vol. 13, pp. 1-40, 2009.

[16] Y. T. Zhuang and H.-C. Wei, and C.-S. Huang, "Educational status of the elderly in Taiwan," in Senior Education Policy and Practice, H.-C. Wei (Ed.), Taipei five South, pp. 121-178, 2008.

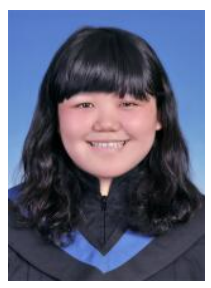

Chien-Hui Yang has graduated from the Department of olden-Ager Industry, Management, Chaoyang University of Technology in 2012. Currently, she is pursuing her master degree in adult and continuing education is the Graduate Institute of Elder Education, in National Chung Cheng University, in Taiwan (ROC) 